\title{
A method for the calculation of the specific gravities of calcium silicates from their refractive indices*
}

\author{
by J. W. Howison, B.Sc. and H. F. W. Taylor, B.Sc., Ph.D.
}

\section{Contribution by J. D. C. McConnell, B.Sc., M.A. (University of Cambridge)}

Howison and Taylor have demonstrated the possible existence of interstices in the plombierite gel samples studied by me. Recent work which I have done shows that a very fine scale pore system does indeed exist. The pore structure has been studied by small angle scattering technique and by the analysis of absorption curves for the gel. The pores appear to be lamellar-of the order of several hundred Angstrom units in lateral extent and

*Pages 13-16 with a width comparable to individual hydrate sheets.

Explanation of the pore system involves a detailed study of the possible mechanism of hydration of the parent dicalcium silicate minerals and this, together with an account of the microstructure of the natural gel, plombierite, I propose to publish shortly.

Reply by the authors

Dr McConnell's observations on natural plombierite gel are of considerable interest as this material seems in many ways to resemble that formed on hydration of cement. His results apparently support and extend our own and the full report of his work will be awaited with interest.

\section{Unbroken tobermorite crystals from hydrated cement*}

by R. Gaze, B.Sc., Ph.D., A.R.I.C. and Robert H. Robertson, M.A., F.G.S.

Contribution by A. E. Moore, M.Sc., A.Inst.P.

(Cement and Concrete Association)

It would be interesting to know whether any diffraction photographs were taken of the preparations described by Dr Gaze and Mr Robertson. If not, the reservations expressed by Dr Jeffery in his comments on the authors' earlier paper ${ }^{(1)}$ would still apply: namely, that these foils cannot be identified as tobermorite on appearance alone.

*Pages 25-26

\section{REFERENCE}

1. GAZE, R. and ROBERTSON, R. H. S. Some observations on calcium silicate hydrate (I)-tobermorite. Magazine of Concrete Research. Vol. 8, No. 22. pp. 7-12. Discussion No. 24. pp. 168.

\section{Reply by the authors}

No electron diffraction photographs were obtained from these preparations. The electron diffraction patterns from more recent preparations involving a hydrothermal reaction of Portland cement and silica clearly identified tobermorite in the form of plates and foils. 